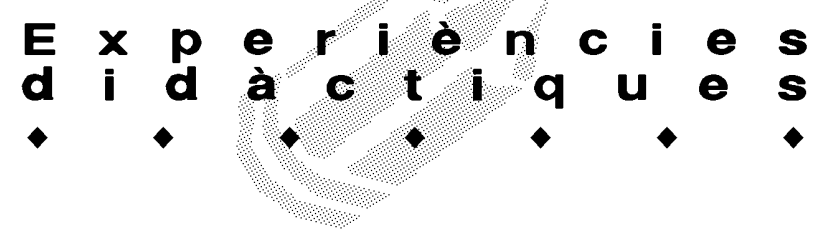

\title{
La música i la dansa per millorar les competències bàsiques
}

\author{
Susanna Suesa i González. M estra de dansa \\ Sara Sánchez i Estivill. Mestra de música \\ CEIP Millenari de Cardedeu (1)
}

\section{Resum}

L'escola M il|lenari, de Cardedeu, fa deu anys es va plantejar com millorar els resultats acadèmics de l'alumnat d'una forma creativa sense augmentar la càrrega lectiva de matèries bàsiques com les matemàtiques o la llengua. Com que es disposava d'un professorat amb una bona formació en música i dansa, i basant-se en investigacions que s'havien realitzat sobre els beneficis de la utilització de la música i la dansa en la formació de les persones, es va decidir incorporar la dansa com a assignatura al llarg de tota l'escolaritat i augmentar la càrrega lectiva de música. Després de l'aplicació completa del projecte s'ha pogut observar que els resultats acadèmics dels alumnes han millorat i, artísticament, són éssers humans més sensibles i creatius.

\section{Paraules clau:}

Didàctica de la música, dansa en contextos escolars, competències, ensenyaments artístics.

\section{Context}

Cardedeu és un poble d'uns 16.000 habitants, de la comarca del Vallès Oriental. Com molts pobles de Catalunya, el nostre ha experimentat un gran creixement en relativament poc temps. El nombre d'immigrants que hi ha al poble no és gaire elevat; principalment són magrebins i sud-americans i, en una proporció menor, xinesos i de països de l'est.

A Cardedeu hi ha cinc escoles públiques d'educació infantil i primària i tres instituts públics.

El CEIP M illenari es troba situat al barri de Can Serra. S'han anat construint habitatges dins del barri i, principalment, hi ha vingut a viure gent de Catalunya. El tant per cent d'immigrants al barri de Can Serra, doncs, és molt petit.

A la nostra escola no tan sols hi ha alumnes del barri, sinó que hi ha alumnes de tot el poble i alguns d'algunes urbanitzacions que, tot i que el poble que tenen més a prop és Cardedeu, no pertanyen a aquest municipi. Actualment, l'escola Mil-lenari és de doble línia i té escolaritzats 456 alumnes, dels quals 156 són d'educació infantil i la resta, de primària. Amb aquest nombre d'alumnes, les ràtios d'algunes classes se situen per sobre dels 25.

El nivell socioeconòmic és molt divers, ja que com que no hi ha cap escola privada o concertada al poble, es produeix molta barreja d'alumnes.

\section{El nostre projecte}

El plantejament d'aquest projecte va venir motivat per la necessitat d'inclusió i potenciació de la música i la dansa a la nostra escola. Els dos àmbits volien fugir de ser un mer aspecte de "guarniment" de l'ensenyament i passar a ser eines per crear els fonaments pel gran potencial educatiu que comporten.

El fet de disposar d'un personal altament qualificat en les matèries de música i dansa, del suport de l'equip directiu i de les famílies del centre va fer que es pogués dur a terme aquest projecte.

La música i la dansa, lluny de ser una tipologia de pràctiques molt especialitzades o desvinculades del marc escolar, ens evidencien el seu gran potencial interdisciplinari i sociocultural, que ajuda a potenciar l'aprenentatge de les competències bàsiques. Els objectius que inicialment ens vàrem proposar van ser els següents:

-Potenciar els ensenyaments artístics (concretament la música, la dansa i la plàstica) per millorar les competències bàsiques.

- Treballar els ensenyaments artístics com a base d'una formació íntegra i harmònica. 


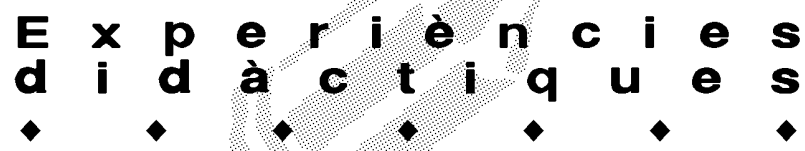

-Desenvolupar la creativitat dels nostres alumnes per conformar una personalitat enriquidora.

L'educació de l'art s'ha concebut sovint com a formació d'artistes i no com a tècnica educativa. A través de l'art construïm la nostra realitat, l'art ens ajuda a conèixer l'entorn. La dansa hauria d'acompanyar l'individu com a recurs didàctic $\mathrm{i}$ creatiu des dels primers anys escolars $\mathrm{i}$ fins i tot, per què no, al llarg de tota la seva vida. Actualment, la funció de la pràctica educativa a l'escola, més que transmetre i oferir informació, ha de situar-se en el procés de reconstrucció del coneixement amb què I'infant arriba a l'aula i, sobretot, potenciar l'actitud positiva envers els aprenentatges.

Reconstruir el coneixement a l'aula no requereix només aproximar conceptes, principis i teories que qüestionin i confereixin sentit a la reorganització de la informació adquirida, sinó també incorporar l'alumne a un procés imprevisible de descobriment i experimentació d'informacions, idees, conductes i valors. Aquesta actitud envers els aprenentatges és el que la dansa i la música veiem que podrien ajudar a estimular, per provocar una obertura de canals de recepció, sobretot en les primeres edats de la infància en què el desenvolupament dels sentits i la plasticitat per atansar-se a la realitat són molt grans. Tot això és una empresa a llarg termini els beneficis de la qual es veurien reflectits en totes les activitats que l'alumnat desenvolupés al llarg de tota l'escolaritat.

\section{Dansa}

Al Ilarg de l'escolaritat tots els nostres alumnes realitzen diferents tipus de dansa: clàssica, tradicional catalana, tradicional d'arreu del món, de diferents èpoques històriques, contemporània i moderna. A través d'aquest treball, i com a aspecte inclusiu en cada un dels estils, l'expressió corporal, la consciència d'un mateix, el ritme, la musicalitat, són els components bàsics per a una educació integral. A través de la dansa ajudem els alumnes a augmentar la capacitat de percepció, ja que la seva sensibilitat s'aguditza. La dansa exerceix un paper pedagògic important com a estimuladora d'autoconfiança. Quan som infants, necessitem moure'ns, perquè moventnos expressem les nostres ganes de riure, de plorar o de jugar. A mesura que creixem, el nostre cos, pels tabús d'una civilització que corromp la nostra necessitat d'expressió, perd cada vegada més el desig d'expressarse mitjançant la música, fent del cos un instrument de comunicació entre el que volem fer, el que podem fer i el que anem "descarregant" per poder-nos expressar. El moviment, unit a l'estímul musical, permet una comprensió total de la música, qüestió que no succeeix quan simplement escoltem. El principal instrument que té la persona és el seu propi cos, a partir del qual podrà tenir experiència de música. Amb la dansa s'adquireix la música a través del cos; amb la mobilització, s'obren les portes de tots els sentits i es comprèn millor el so, no a través d'una teoria estàtica, sinó de forma global, de

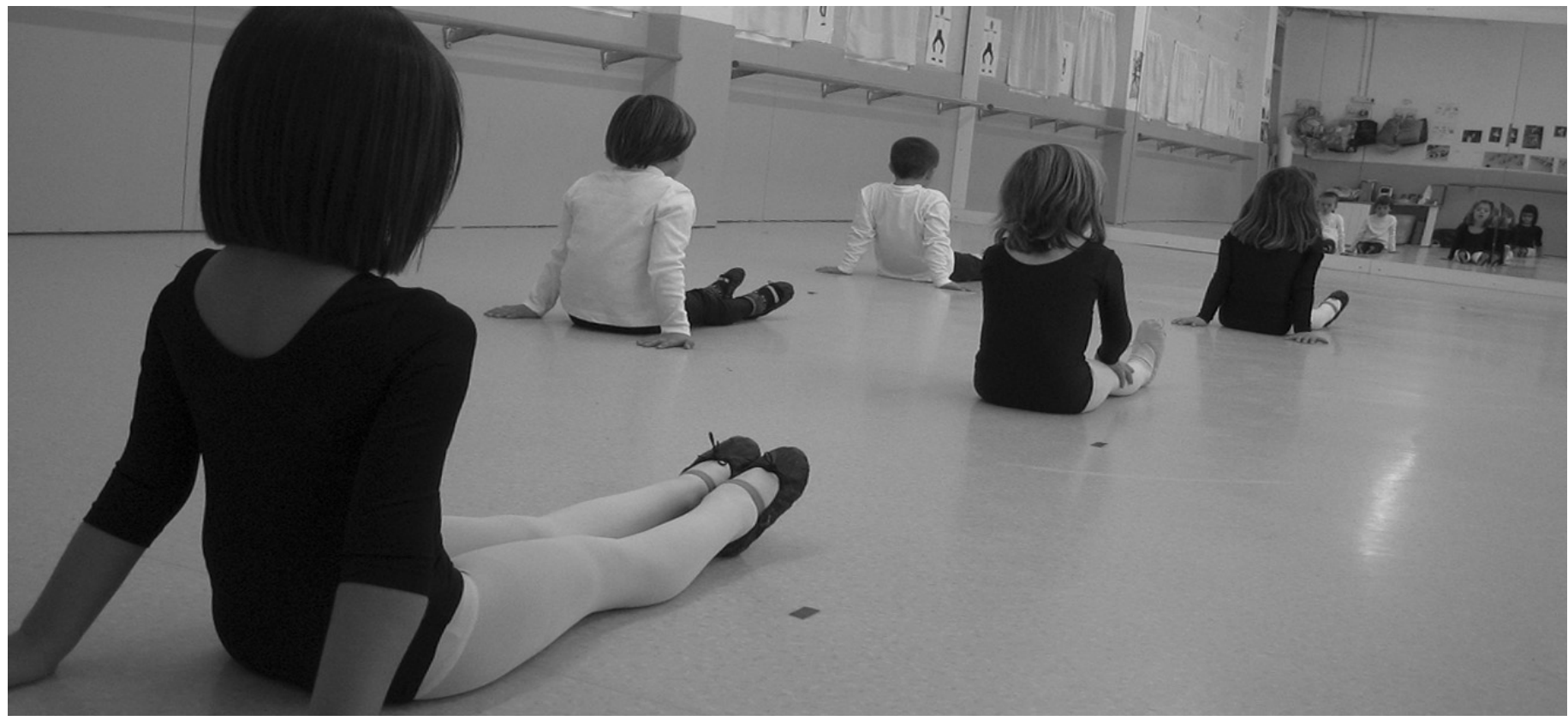




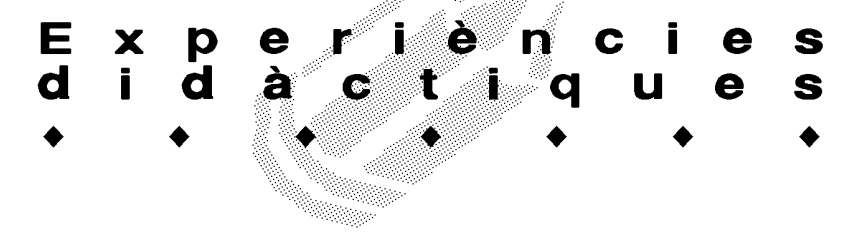

través d'una teoria estàtica, sinó de forma global, de manera que la música es transforma en quelcom viu que ens permet sentir-la des del més profund. El moviment del cos amb la música mostra aspectes amagats d'aquesta que estan ocults a l'oïda i a la intel-ligència. Dansar no és, doncs, un guarniment en l'educació, sinó un mitjà paral.lel a les altres disciplines que formen, en conjunt, l'educació de la persona.

\section{Educació infantil: ballet clàssic}

El ballet clàssic es realitza a l'educació infantil perquè es considera una bona base per treballar aspectes de coneixement del propi cos, control postural, ordre i disciplina. Al llarg d'aquests tres anys es fa un seguiment dels alumnes i s'orienta els que volen continuar extraescolarment la dansa clàssica a partir de primer. El ballet, en les primeres edats, facilitarà l'obertura per percebre l'entorn i anar-se diferenciant-s'hi amb l'autoconeixement i apreciació de les característiques que li són pròpies. El fet de fer ballet a l'escola ens ofereix la possibilitat de conèixer el propi cos, les seves característiques funcionals i els seus límits. La consciència corporal que es va adquirint a poc a poc al Ilarg de la vida ens ajudarà a comprendre millor la realitat en què vivim. L'infant que dansa es torna més obert a la comprensió de l'entorn, i això es reflecteix en la seva relació amb els aprenentatges.

Les característiques pròpies del ballet clàssic ens donen unes eines excel·lents per treballar el propi cos, la música i la disciplina.

Les sessions de ballet s'estructuren en quatre parts:

a. Els exercicis de la barra: serveixen per escalfar el cos i preparar-se per als estiraments. Aquí treballem la lateralitat, les parts del cos i els seus moviments.

b. Els estiraments: treballem la flexibilitat i les possibilitats de moviment que té cada part del cos.

c. Els exercicis al centre: sense barra, ens permeten descobrir el propi equilibri.

d. La coreografia: aprenem un ballet que ens permet organitzar-nos en l'espai i el temps, amb uns moviments concrets i amb una música determinada. Al final del cicle es fa una sessió oberta a pares i mares que fa de cloenda de tot aquest treball.

\section{Cicle inicial de primària: dansa tradicional i expressió corporal}

Al cicle inicial es treballa la dansa tradicional, oferint als alumnes uns ritmes i unes músiques ben diferents al ballet clàssic. Aquí es treballa més el grup i la socialització, a més de ser un element d'integració. A part d'això, i per no trencar amb la dansa clàssica feta en cursos anteriors, es fa un treball de ritme i d'expressió corporal. Aquest treball ajuda tots els nostres alumnes i també els que han optat per seguir els estudis de dansa clàssica en una activitat extraescolar, sense crear desnivells entre els uns i els altres. Utilitzem la música com a estimulador i ajudem els alumnes a representar-la; allò que senten per dintre ha d'arribar a tots els racons del seu cos i, alhora, sortir enfora en forma de dibuix corporal, de moviment. Al final de curs es fa una trobada de dansa en què es mostren les danses tradicionals que s'han treballat. Aquests alumnes també participen mostrant el que estan fent a dansa en les celebracions de festes, com ara Santa Cecília o Sant Jordi.

\section{Cicle mitjà de primària: dansa d'arreu del món i dansa històrica}

A tercer curs de primària es realitzen danses tradicionals de diferents països del món. Tenen per objectiu donar a conèixer diferents cultures, a més de músiques i ritmes diferents. Tot passant pels cinc continents es fa un treball exhaustiu del moviment, trencant a vegades estructures pròpies per descobrir noves formes de representació. El treball de relació grupal i de disciplina social hi és molt present.

A quart curs de primària es realitzen danses de diferents èpoques històriques, que apropen l'infant a l'època que es treballa d'una forma distesa i amena. Apropar la història als infants sempre ha estat una tasca àrdua per als ensenyants i fer-ho d'aquesta forma és força enriquidor. Talment com les danses d'arreu del món, situen l'infant en un paradigma diferent al seu i això fa que es tornin més oberts en la seva relació amb el coneixement. Al final de cada curs es realitza un espectacle al teatre del poble per mostrar al públic general tot allò que s'ha fet al llarg del curs. Els espectacles no són un objectiu, sinó una finalitat, el final de tot un procés d'aprenentatge en què aquest procés és el més important. M algrat això, el fet d'actuar amb un vestuari i una escenografia en un teatre ple de gent situa l'alumne en una situació de superació i d'enfrontament amb ell mateix per poder 


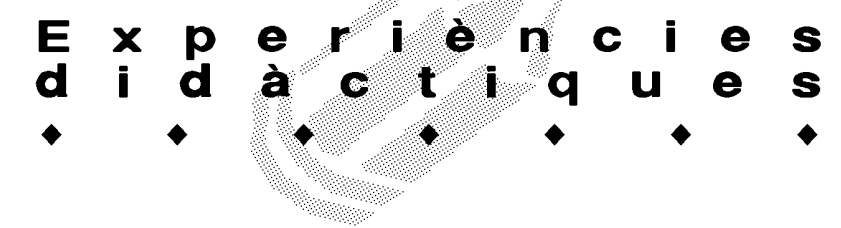

\section{Cicle superior de primària: dansa contemporània i dansa moderna}

A cinquè curs els alumnes realitzen dansa contemporània. Amb tot el bagatge anterior ara ja tenen suficients recursos per començar a crear. La dansa contemporània permet a l'infant crear i cercar els propis moviments. Cal que el cos participi en la seva totalitat per obtenir una autèntica comunicació. Per això és necessari desenvolupar en l'infant el desig de crear i la plena consciència de les actituds, les que prenem espontàniament en la relació de la vida de cada dia i les que són directament volgudes per expressar un element precís.

La dansa contemporània és la Ilibertat màxima del moviment, la recerca personal de l'energia, el constant esperit d'investigació que domina els nostres temps duentnos a qüestionar tots els llenguatges artístics. En la dansa contemporània, la dinàmica corporal prové de l'energia de la persona fent que el moviment arribi a cada part del cos. L'espai és utilitzat com una via natural d'expressió a través de cada gest i del dinamisme del moviment.

A sisè curs els alumnes realitzen dansa moderna. Aquest tipus de dansa és la que més s'adapta als seus interessos;

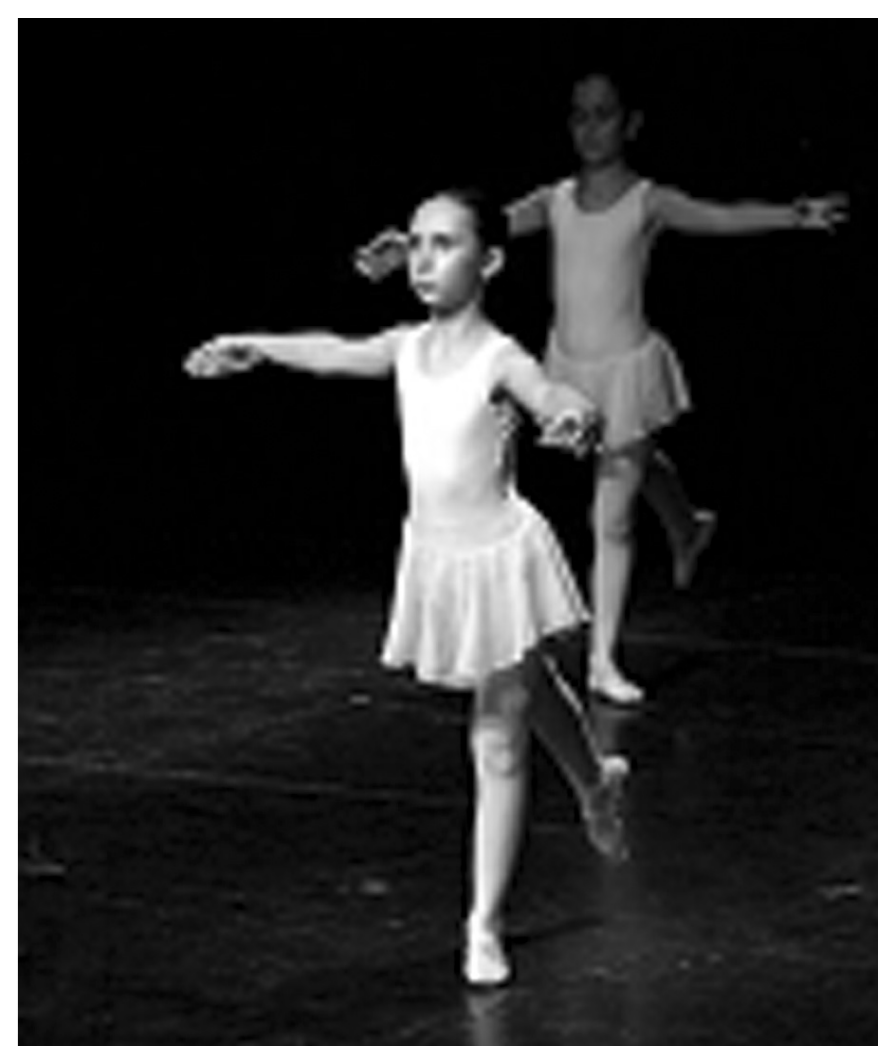

per aquest motiu, estan molt motivats per realitzar-la. El treball que es fa torna a ser bastant individual, però de totes les expressions individuals surt una escenificació collectiva.

Tot el treball realitzat es mostra en diferents festes al Ilarg del curs.

\section{Música}

Totes les persones som músics per naturalesa, o sigui, naixem amb aquesta capacitat (intel-ligència musical, una de les múltiples intel-ligències, establertes per Howard Gardner). Que la desenvolupem més o menys, ja depèn de molts factors. Però en tenir-la, fins i tot hem pogut demostrar que és un mitjà excel-lent per conduir una educació basada en el desplegament de les capacitats humanes innates. La música activa més zones cerebrals que cap altre mitjà d'aprenentatge, tot facilitat la comprensió d'allò que cal aprendre. No hi ha cap cultura ni ètnia sense música, la qual cosa fa que esdevingui un mitjà universal que facilita la globalització dels processos socialitzadors (especialment indicats en col-lectius de barreja ètnica i en els casos d'adopcions d'infants d'altres cultures). La música troba en la cançó la unió d'allò emocional amb allò cognitiu, dos dels pilars bàsics de tota educació escolar.

La música és terapèutica per ella mateixa (això ja fa vinti-cinc segles que ho van establir els filòsofs i metges de la Grècia clàssica); per això és el millor mitjà per atendre patologies d'origen emocional i somàtiques, somàtiques d'origen neuronal, somàtiques d'origen terminal (oncològiques, estats de coma) i les d'origen emocional i espiritual (depressions, tristesa, angoixa). La música, utilitzada com un eix transversal dins del currículum escolar, ens atorga una possibilitat d'or per fer una tasca educativa més fructífera (els objectius s'assoleixen amb més rapidesa i, sobretot, amb més perennitat), més centrada en l'art (entès com a expressió natural de l'ésser humà), però sense perdre la possibilitat del pensament científic. La música és un mitjà educatiu excel·lent per contemplar l'ésser humà com un tot, alhora que permet ajudar-lo a atansar-se a la realitat d'una manera molt més directa: d'aquí que sigui tan important a qualsevol edat $i$, en especial, a la infància i a l'adolescència, el gran moment de les cançons que queden escrites en la nostra memòria emocional.

A l'educació infantil es considera un element de sensibilització. Es treballen les cançons (mostrades d'una 


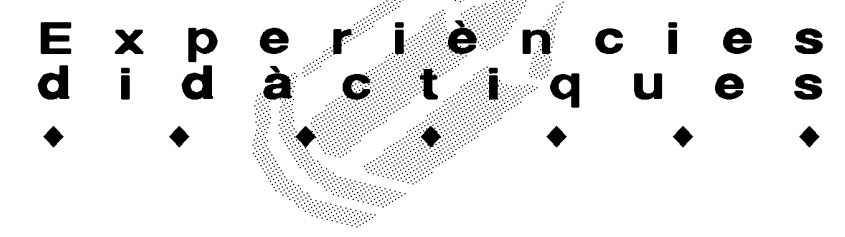

forma correcta quant a afinació i dicció; encara que els alumnes no siguin capaços de fer-ho així, sí que són capaços de sentir-ho), les audicions (aprenent a escoltar i a representar la música), el moviment corporal (a part del ballet, que els ajudarà a entendre els patrons rítmics) i els instruments, tot d'una forma globalitzada i amb l'objectiu d'anar creant uns fonaments tant per als alumnes que en un futur s'hi vulguin dedicar d'una forma específica, com per a aquells per a qui només esdevingui part de la formació personal.

Dins l'àrea de música destaquem els eixos troncals següents: la cançó, el llenguatge musical, l'audició, la pràctica instrumental i la informàtica musical. El desplegament d'aquests cinc apartats són la base de la nostra formació musical. S'hi dediquen dues sessions setmanals a cicle inicial i tres a cicle mitjà i superior, una dedicada a la música en general - on es treballen l'audició, la cançó i el llenguatge-, una d'instrumentació i una d'informàtica musical (les dues últimes realitzades amb la meitat del grup classe).

\section{La cançó}

És el més important com a base de tot l'ensenyament musical a la primària. La treballem centrada en les festes tradicionals o de les de la mateixa escola i també englobada en cantates o festivals.

El resultat que esperem a final de la primària és que els nostres alumnes tinguin una bona predisposició a l'hora de cantar (afinació, dicció i atenció al director/a) i que mostrin una actitud positiva per interpretar qualsevol estil del repertori partint de les cançons tradicionals catalanes, d'arreu del món i les d'estil més modern (no es posen límits a l'hora de triar el repertori, ni de toanlitat, ni d'origen, ni d'estil).

\section{Llenguatge musical}

El llenguatge musical és un aspecte que treballem des del cicle inicial en dos àmbits: sensorial i escrit. A cicle mitjà, els nostres alumnes han de tenir un cert domini de la lectura musical, escala de do major, conèixer i començar a llegir les notes fora del pentagrama - línies addicionals-, saber interpretar diversos ritmes, començar a saber diferenciar els intervals majors i menors, les lligadures i les diferents dinàmiques musicals. A cicle superior, els alumnes utilitzen les escales de do major, sol major i fa major; es treballa el pentatonisme, I'harmonia, els intervals de 2a i 3a majors i menors;



s'amplia el coneixement de les notes en clau de fa, i s'amplia la pràctica de ritmes, aplicant els acords més bàsics per acompanyar melodies.

El llenguatge musical es reforça amb la informàtica musical, tant amb els programes d'edició de partitures (M usic Time) amb els més lúdics (karaokes, Acids...) i amb la pràctica instrumental Orff, en què treballem l'harmonia, tocant en petits grups instrumentals.

\section{L'audició}

Aprofitant dates especials com Santa Cecília, Nadal, Sant Jordi i d'altres moments que ens proporciona la vida escolar, organitzem audicions protagonitzades pels alumnes, concerts dins de l'escola que ens ofereixen diversos artistes convidats i sortides per veure actuacions al Palau de la Música Catalana, a l'Auditori o al Gran Teatre del Liceu.

\section{Pràctica instrumental}

Els instruments Orff els comencem a treballar amb petits grups instrumentals. A partir de cicle mitjà, a través d'un centre d'interès; a tercer, danses i músiques d'arreu del món, i a quart, història de la música i la dansa. Aquests dos projectes són el motiu per treballar l'harmonia, els 


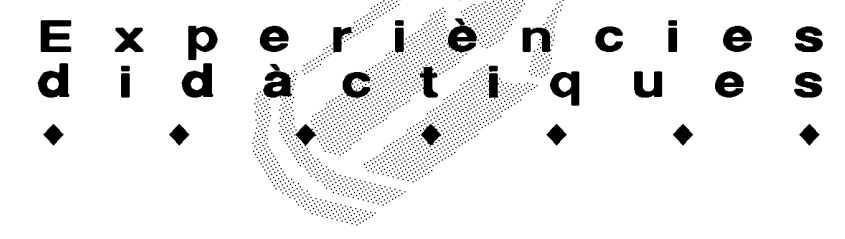

diferents ritmes, la sincronització a l'hora de tocar i molts altres aspectes implícits.

A cicle superior es toquen diferents estils - clàssic, jazz, temes de pel·lícules, música catalana, entre altres- que van sorgint al llarg del curs i que creiem que són interessants per treballar amb els instruments, i amb els quals els nens i nenes mostren més motivació. Sovint s'utilitzen propostes dels mateixos alumnes. A part de participar amb els grups d'instruments en festes i concerts al llarg del curs, enregistrem les peces que toquem a l'escola amb programes d'enregistrament i estem creant un petit banc de cançons propi de l'escola. En el cas dels nois i noies de cicle superior, tenen I'oportunitat d'endur-se les cançons amb els seus MP3, M P4, Ipod o llapis de memòria.

\section{Informàtica musical}

La informàtica musical és una eina més per reforçar els diferents aprenentatges dins l'àrea de música; per tant, des de l'educació infantil, ja l'utilitza el mestre com a reforç de cançons, per complementar les qualitats del so, per a audicions...

A cicle inicial de primària s'utilitza com a complement a l'àrea de música, ja que és el moment en què els nens i nenes comencen a realitzar les primeres activitats musicals que ens ofereix l'Edu365, relacionades amb el llenguatge, l'audició i la cançó.

A cicle superior treballem diferents programes informàtics (de programari lliure, que els nois i noies poden descarregar d'Internet de forma gratuïta), com el Music Time, que és un editor de partitures; I'Audacity, on treballem el so, i programes musicals més lúdics com I'Acid i els karaokes, entre altres, sempre amb l'objectiu de reforçar i complementar els diferents continguts de l'àrea de música.

La finalitat de la informàtica musical és proporcionar als nens i nenes les eines bàsiques per poder compondre petites cançons amb una estructura - per exemple ABA, amb una melodia senzilla, on utilitzen les notes i ritmes que ells coneixen-, saber quins acords poden utilitzar per fer l'acompanyament harmònic, afegir-hi una part rítmica (bateria) realitzada per ells o senzillament utilitzar una base rítmica en format M IDI.

Tots els nostres alumnes tenen accés al desplegament d'aquests cinc apartats troncals de l'àrea de música; per tant, quan acaben l'escola de primària gaudeixen d'un coneixement bastant ampli de la música, amb la petita pretensió per part de l'escola que en un futur siguin uns consumidors amb criteri de la cultura musical i de tots els diferents vessants culturals, ja que actuen de forma molt important en el desenvolupament i creixement de les persones. 0 , fins $i$ tot, que alguns d'ells hi participin de forma activa tocant algun instrument com a afecció o de forma professional.

\section{Valoració. Resultats del projecte}

Aquest curs marxen els primers alumnes que han realitzat el projecte des de P-3. És, doncs, un curs de valoració i avaluació dels resultats obtinguts. S'ha observat una millora en els resultats globals dels aprenentatges; evidentment, no es pot afirmar que sigui exclusivament pel fet d'haver participat en aquest projecte, però sí que han obtingut un nivell de dansa i música que, si no hagués estat pel treball fet al Ilarg dels nou anys d'escolarització, no hauria estat possible.

La nostra pretensió és que en un futur els nostres alumnes siguin uns consumidors d'art amb criteri. Que puguin valorar i ser partícips de tota expressió artística, convertintse en persones actives davant qualsevol música, dansa, pintura, escultura..., ja que durant la seva escolarització han anat interioritzant les eines mínimes necessàries. I tot aquest treball també els ha ajudat a millorar en els seus aprenentatges, que es veuran reflectits en la seva futura vida acadèmica.

Notes

\section{(1). http://blocs.xtec.cat/muda2/}

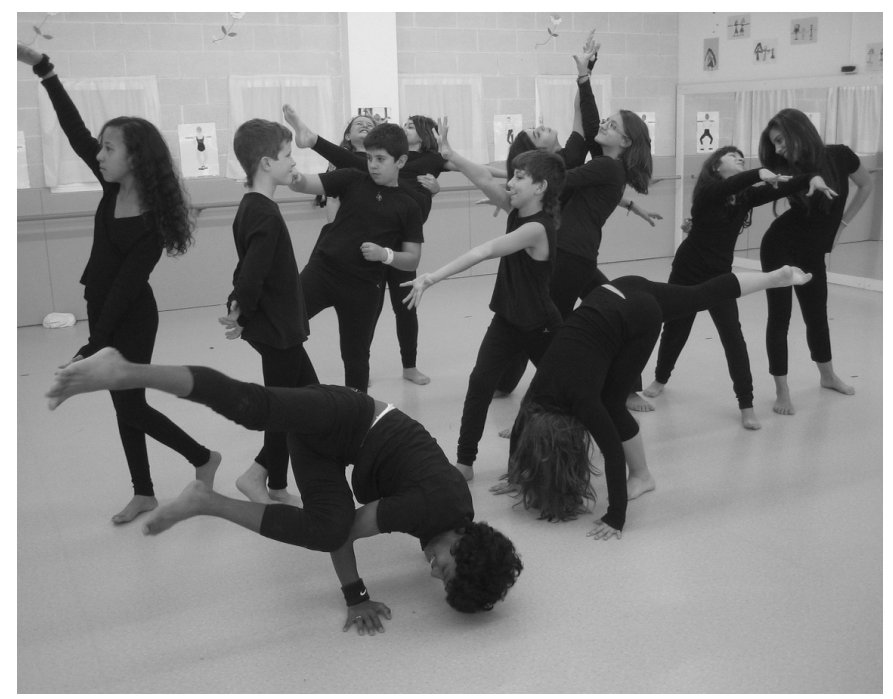

